\title{
DRINKING PATTERNS AND DRUNK-DRIVING BEHAVIOUR IN CATALONIA, SPAIN: A COMPARATIVE STUDY
}

\author{
Manuela Alcañiz ${ }^{\mathrm{a}}$, Miguel Santolino ${ }^{\mathrm{b}}$, Lluís Ramon ${ }^{\mathrm{c}}$ \\ a Department of Econometrics, Riskcenter-IREA, University of Barcelona \\ Diagonal 690, E-08034 Barcelona, Spain \\ e-mail: malcaniz@ub.edu \\ ${ }^{b}$ Department of Econometrics, Riskcenter-IREA, University of Barcelona \\ Diagonal 690, E-08034 Barcelona, Spain \\ e-mail: msantolino@ub.edu \\ ${ }^{c}$ Catalan Traffic Authority, Generalitat de Catalunya \\ Diputació 355, E-08009 Barcelona, Spain \\ e-mail:1ramon@gencat.cat
}

Corresponding author:

Manuela Alcañiz

Department of Econometrics, Riskcenter-IREA

University of Barcelona

Diagonal 690, E-08034 Barcelona, Spain

Telf.: (+34) 934021983

e-mail:malcaniz@ub.edu

Journal:

Transportation Research Part F: Traffic Psychology and Behaviour

Special Issue:

Field Studies in Traffic Safety Behaviour 


\begin{abstract}
:
This study explores three alcohol-related databases so as to provide a comprehensive understanding of drinking patterns and the prevalence of alcohol-impaired driving in Catalonia (Spain). The rate of alcohol-impaired drivers is compared with the percentage of drinkers in this population, with a particular focus on heavy episodic drinkers. Two strategies adopted by law enforcement agents when conducting alcohol breath tests are examined: i) non-random and ii) random approaches to roadblock location and driver selection. We find that heavy drinker profiles (in terms of age and gender) closely match those of alcohol-impaired drivers detected at strategically located, non-random sobriety checkpoints (especially in the case of female drivers), and that they also correlate with the age-gender distribution of drivers involved in road accidents with victims. Different drink driving patterns are detected when sobriety checkpoints are located randomly and drivers are tested at random. Older drivers are identified as a risk group as they abandon the safer driving habits in relation to alcohol shown when they were middle-aged. A combination of non-random and random controls would increase driver perception of their chances of being detected when drink driving. As such, the whole population, regardless of their drinking profile, would be alerted to the serious personal, social and legal implications of alcohol-impaired driving.
\end{abstract}

\title{
Highlights:
}

- Traditional non-random alcohol breath testing is primarily effective for detecting binge-drinking patterns among young drivers.

- Random alcohol breath testing enhances the detection of the drink driving profiles in the population.

- The middle-aged present low levels of alcohol consumption (especially, females) and impaired driving rates, suggesting that parenthood has a significant impact on drinking patterns and drunk-driving behaviour.

- Elderly drivers are a group at risk of drink driving.

Keywords: Alcohol; drink driving; sobriety checkpoints; random breath testing; drinking patterns; heavy episodic drinking. 


\section{INTRODUCTION}

\subsection{Aims and scope}

Abusive alcohol intake is a major public health risk for populations worldwide, particularly those in developed societies (Room, Babor \& Rehm, 2005; WHO, 2011). The consumption of alcohol can lead to impulsive actions by impairing the inhibitory mechanisms that normally promote socially appropriate behaviour (Marczinski \& Fillmore, 2003). Such disinhibited actions are especially dangerous while driving, as they contribute to aggressive and risky behaviour, particularly among young drivers (Fillmore, Blackburn \& Harrison, 2008). In addition, alcohol impairs a driver's psychomotor performance, visual perception and coordination. As a result alcohol stands out as the most prevalent psychoactive substance among injured and killed drivers involved in road accidents (Isalberti et al., 2011).

In this paper we investigate the relation between drinking patterns and impaired driving behaviour in Catalonia (Spain). Our goal is to provide insights into alcohol drinking behaviour and the decision to drive drunk in relation to an individual's age and gender. To do so, we examine three official alcohol-related databases for the year 2012, and compare the percentage of drinkers in the population with the rate of illegal outcomes in random and non-random roadside alcohol tests. Random breath tests (RBT) differ from non-random breath tests (non-RBT) in their sample selection method, the former taking a probabilistic approach and the latter adhering to police officer criteria. We focus on the efficiency of sobriety checkpoints to detect alcohol-impaired drivers and to prevent road accidents, according to the randomness (or intentionality) in the selection of the tested driver. Specifically, we seek to determine whether there are alcohol risk profiles in the population not properly identified by traditional breath tests, in which traffic officers typically test drivers that arouse suspicions of drunk driving or those involved in an accident. 


\subsection{Background}

Most studies in the literature to date analyse the drinking behaviour and drunk driving patterns of a population separately. Moreover, to the best of our knowledge, no previous attempts have been made to compare individuals' self-reported drinking behaviour and the drunk-driving patterns observed in RBT and non-RBT procedures to determine which breath-test strategy is more effective.

Spain's culture of alcohol consumption has traditionally adhered to the Mediterranean drinking pattern, with a relatively high proportion of daily alcohol intake with meals, and the avoidance of irregular heavy drinking (Rehm et al., 2013). In recent years, however, this pattern seems to have undergone a change with an increase in heavy episodic (binge) drinking being detected in both genders (Valencia-Martín, Galán \& Rodríguez-Artalejo, 2007). This behaviour is typified, above all, by the consumption of spirits by Spanish youth and young adults as they socialise in public places (the socalled "botellón"). The harmful, long-term effects of binge drinking on health are well known, especially among adolescents and youth (Naassila et al., 2013) and, moreover, the literature has long warned of the strong association between binge drinking and impaired driving (Duncan, 1997) and fatal crashes (Voas et al., 2006). For instance, Flowers et al. (2008) have shown that $88 \%$ of alcohol-related driving episodes in the United States involved this drinking pattern. Also in the US, Naimi, Nelson and Brewer (2009) provide the following profile of the binge drunk driver: male, aged 35-plus and typically drinking in bars or clubs, although this profile of binge drunk drivers may be country-specific.

In order to reduce the prevalence of individuals driving under the influence of alcohol, national road safety policies in most countries make it a priority to deter drivers from drinking by making them aware of the risks involved (McCarthy \& Tay, 2005). To determine whether drivers respect the maximum blood alcohol content (BAC) level, it is common practice to locate sobriety checkpoints at previously unannounced locations alongside roads and in urban areas (Dula, Dwyer \& LeVerne, 2007). At these selected locations, traffic officers then choose at their discretion which vehicles to pull over, and whether to perform the test or not on the driver. The effectiveness of this practice in reducing the number of alcohol-related crashes has been demonstrated in countries as 
diverse as the United States (Fell, Lacey \& Voas, 2004), Thailand (Ditsuwan et al., 2013), Cuba (Garcell et al., 2008) and Australia (Peek-Asa, 1999). Erke, Goldenbeld and Vaa (2009) conducted a meta-analysis of 40 studies and concluded that sobriety checkpoints reduce alcohol-related crashes by $17 \%$, and all crashes by between 10 to $15 \%$. They claim that testing all drivers that are stopped may improve the effectiveness of such controls, as this would eliminate the possibility of faking normal driving behaviour.

As the drivers tested at traditional sobriety checkpoints are not randomly selected, they cannot be considered to be representative of the drinking and driving patterns on the roads. The subjectivity incurred by an officer when selecting a driver to stop can result in the non-detection of certain profiles of drink driving offenders (Wells et al., 1997). To counter this limitation and to alert the whole driving population to the risks of driving under the influence of alcohol, some countries have developed an alcohol detection strategy based on the random allocation of sobriety checkpoints across the territory, and the performance of a breath alcohol test on the first driver to approach an empty road block, whatever their gender, age, type of vehicle or observable driving performance (Gjerde et al., 2008; Lacey et al., 2011; Vanlaar, 2005). RBTs have the advantage of alerting the whole population to the possibility of being detected while driving under the influence, since the perceived risk increases (Löbmann, 2002). This serves as a major deterrent across the population strata (Homel, 1988), regardless of an individual's personal characteristics, or the time of the day when driving. Australia introduced RBT procedures in the early 80 s and today is considered to have one of the most successful programs in the world in terms of reducing the number of crashes (Erke et al., 2009). Ferris et al. (2013) attribute Australia's success to high intensity enforcement, extensive publicity and a high visibility policy thanks to the use of custom-built "booze buses" that allow a high number of tests to be performed per hour and on-site processing. As a result, the number of drivers willing to risk detection for drink driving has fallen dramatically and, in turn, the number of alcohol-related crashes has been reduced. 


\section{DATA AND MEASURES}

\subsection{Geographical area}

The geographical area covered in this study is Catalonia, a Mediterranean region located in the northeast corner of Spain, whose capital and largest city is Barcelona. In 2012 the region had a population of more than 7.5 million inhabitants (2012), while the total number of vehicles exceeded 5.0 million and the number of drivers at the end of that year was over 4.1 million (Spanish Traffic Authority, 2012). In 2012 there were 336 traffic fatalities in Catalonia and 31,630 people injured (1,980 severely) in a total of 23,368 motor crashes with victims. Although the number of deaths had fallen by $48 \%$ since 2005, toxicological analyses showed that an alarming $29 \%$ of these drivers in 2012 had a BAC level over the legal limit (Catalan Traffic Authority, 2012), hence the imperative need for improved drink driving control strategies.

\subsection{Drunk-driving legislation}

Spain's driving legislation is applicable in Catalonia, fixing a minimum legal age for driving motor vehicles at 18 , with the exception of mopeds (equipped with a motor of less than $50 \mathrm{cc}$ ) that can be driven in urban areas at age 15. Law enforcement officers are allowed to stop any driver at their own discretion and require them to take a BAC test, whether or not they present any visible signs of impairment.

Statutory blood-alcohol limits for driving differ between countries within Europe. Spanish legislation differentiates between administrative- and criminal-positives, according to the level of alcohol concentration in the breath or blood. Administrativepositives are recorded by drivers with a breath alcohol content (BrAC) between 0.25 and $0.60 \mathrm{mg} / 1$ (0.15 and $0.60 \mathrm{mg} / \mathrm{l}$, for novice and professional drivers), and they face administrative penalties if detected. If the BrAC level is over $0.60 \mathrm{mg} / \mathrm{l}$ drivers are deemed to have committed a criminal offence and face much sterner legal sanctions, including the temporary suspension of their driving licence and imprisonment. BrAC values are related to BAC levels expressed in grams per litre of blood; however, there is 
no directly proportional constant between these two magnitudes (Jones, 2010). The average blood/breath ratio of alcohol used in Spain is 2:1. Hence, standard BAC legal limits are $0.50 \mathrm{~g} / \mathrm{l}$ and $1.20 \mathrm{~g} / \mathrm{l}$, respectively. BAC notation is used henceforth in this article as is customary in the international literature. Here, drivers with a BAC level over the legal limit are defined as driving under the influence of alcohol (DUI). Some authors, such as Dula et al. (2007), point out that the general impact of the deterrent depends upon the degree to which potential DUI drivers are made aware of the consequences of being caught driving while intoxicated. In this article we investigate the characteristics of DUI offenders but we do not differentiate the type of offence committed and the associated punishment (administrative penalties for BAC levels between $0.50 \mathrm{~g} / 1$ and $1.20 \mathrm{~g} / 1$, and criminal offences for BAC levels above $1.20 \mathrm{~g} / \mathrm{l}$ ).

\subsection{Alcohol-related databases: complementary sources}

Three official sources of alcohol-related data were used to examine the relationship between drink patterns and drunk-driving behaviour in Catalonia.

\subsubsection{Catalan Health Survey}

The alcohol consumption habits of the general population as well as the characteristics of heavy episodic drinkers were examined by means of the Catalan Health Survey (ESCA, Catalan Health Department, 2012). This is an official survey providing extensive information on the health of individuals in relation to a set of sociodemographic variables. The first ESCA was carried out in 1994 and since 2010 it has been performed on a semester basis. The sample uses a semi-annual stratified design, based on age, gender and geographical area (Alcañiz et al., 2014b). The random collection of the data is performed using personal interviews, and the questionnaires of each time-period are designed to be comparable.

The survey deals, among many other topics, with population lifestyles regarding health, including self-reported alcohol intake. Individuals are asked about their frequency of alcohol consumption on weekdays and holidays over the preceding 12 months. Four types of alcoholic beverages are distinguished: beer; wine or similar; shots or fruity 
liquors; and spirits. Respondents are also questioned as to how many times they consumed five or more drinks on one specific occasion, which enables episodes of binge drinking to be identified. According to the Spanish Society of Family and Community Medicine, drinkers present binge behaviour if they consume more than five standard drink units (SDUs) in 24 hours at least once a month, whatever their gender ${ }^{1}$ (Robledo \& Córdoba, 2005).

In this study, we used the ESCA-2012 sample comprising the data for 3,670 individuals aged 18-plus. Individuals were classified as 'non-drinkers', if they reported not drinking alcohol; 'drinkers', if they claimed that they drank some alcohol; and 'binge drinkers', if they admitted having drunk more than five SDUs on one specific occasion at least once a month.

\subsubsection{Random breath tests}

Alcohol related data from a sample of RBTs carried out by police officers on interurban roads in Catalonia in 2012 were analysed. The roadside survey was designed with the aim of determining the DUI percentage for the whole Catalan driving population by road type, day of the week, time of the day and other factors. A two-stage sampling process was performed. First, sobriety roadblocks were placed on randomly selected road sections. Secondly, drivers passing these sobriety checkpoints were randomly stopped by traffic officers and tested for alcohol following the standard procedure. A sample of 9,836 drivers was alcohol breath-tested. Outcome results showed that the percentage of DUI was approximately a third of the rate found in non-RBT. Further details on the design of the stratified probabilistic sample to represent vehicles circulating in Catalonia can be found in Alcañiz et al. (2014a).

\subsubsection{Non-random breath tests}

Population data from 472,073 non-RBTs carried out in 2012 in Catalonia were provided by traffic authorities. The database consists of 455,591 preventive BAC tests -

\footnotetext{
${ }^{1}$ The Spanish-SDU is equivalent to $10 \mathrm{gr}$ of pure alcohol.
} 
performed at checkpoints sited at strategic locations and during high-risk time-slots, involving the intentional selection of drivers - and 16,482 tests carried out on drivers following motor accidents involving victims. These tests represent almost $99 \%$ of the total number of non-RBTs, while the remaining $1 \%$, which we did not consider here, included breath tests conducted for such reasons as drivers showing visible signs of alcohol intoxication or after committing a traffic violation.

The alcohol-related data used in the study are differentiated by age and gender as shown in Table 1. Age was measured in five-year intervals from 25 until 64 years. A further age-differentiation for under 25 year olds and over 64 year olds was not considered due to the relatively low case numbers for these age groups. It should be noted that, on average, approximately four of every five BAC tests were carried out on male drivers, for all of the different types of breath tests, reflecting their much higher presence on Catalan roads.

Table 1. Sample size of alcohol-related data sources in Catalonia by gender and age interval, 2012.

\begin{tabular}{lrrrrrrrr}
\hline & \multicolumn{2}{c}{$\begin{array}{c}\text { ESCA - Population } \\
\text { drinking habits }\end{array}$} & \multicolumn{2}{c}{ RBT } & \multicolumn{2}{c}{$\begin{array}{c}\text { Non-RBT } \\
\text { (preventive) }\end{array}$} & \multicolumn{2}{c}{$\begin{array}{c}\text { Non-RBT } \\
\text { (accident) }\end{array}$} \\
\hline Age & \multicolumn{1}{c}{ Men } & Women & \multicolumn{1}{c}{ Men } & Women & \multicolumn{1}{c}{ Men } & Women & Men & Women \\
\hline$<25$ & 157 & 150 & 748 & 292 & 53,370 & 17,494 & 1,732 & 628 \\
$25-29$ & 151 & 143 & 820 & 275 & 53,824 & 15,647 & 1,410 & 519 \\
$30-34$ & 198 & 195 & 907 & 344 & 56,438 & 13,933 & 1,757 & 545 \\
$35-39$ & 176 & 178 & 1,531 & 268 & 58,007 & 11,500 & 1,684 & 505 \\
$40-44$ & 212 & 178 & 1,149 & 246 & 50,992 & 9,086 & 1,584 & 421 \\
$45-49$ & 155 & 144 & 1,055 & 169 & 36,664 & 5,843 & 1,254 & 313 \\
$50-54$ & 169 & 158 & 679 & 98 & 29,131 & 4,015 & 1,094 & 222 \\
$55-59$ & 138 & 132 & 477 & 103 & 16,609 & 2,042 & 827 & 166 \\
$60-64$ & 121 & 130 & 289 & 39 & 10,825 & 1,158 & 629 & 123 \\
$>64$ & 373 & 412 & 315 & 31 & 8,144 & 869 & 950 & 119 \\
\hline Total & 1,850 & 1,820 & 7,971 & 1,865 & 374,004 & 81,587 & 12,921 & 3,561 \\
\hline
\end{tabular}

$\mathrm{ESCA}=$ Catalan Health Survey; RBT=Random breath tests. 


\section{RESULTS}

Self-reported alcohol drinking habits and DUI rates - according to the random nature and the purpose of the BAC tests - were examined by gender and age in 2012 for the Catalan population. The results are shown in Table 2 and Figure 1.

Table 2. Drinking habits and percentage of DUI drivers according to the purpose of the breath test, by gender and by age, $2012^{\mathrm{a}}$.

\begin{tabular}{|c|c|c|c|c|c|c|c|}
\hline & \multirow[b]{2}{*}{ Age } & \multicolumn{3}{|c|}{ Population drinking habits (\%) } & \multicolumn{3}{|c|}{ Impaired in breath tests $(\%)$} \\
\hline & & $\begin{array}{c}\text { Non } \\
\text { drinkers }\end{array}$ & Drinkers $^{\mathrm{b}}$ & $\begin{array}{c}\text { Binge } \\
\text { drinkers }\end{array}$ & RBT & $\begin{array}{c}\text { Non-RBT } \\
\text { (preventive) }\end{array}$ & $\begin{array}{l}\text { Non-RBT } \\
\text { (accident) }\end{array}$ \\
\hline \multirow{11}{*}{$\underset{z}{Z}$} & $<25$ & 22.2 & 77.8 & 6.8 & 0.9 & 5.8 & 18.7 \\
\hline & $25-29$ & 14.8 & 85.2 & 17.2 & 2.6 & 4.6 & 15.2 \\
\hline & $30-34$ & 23.3 & 76.7 & 9.7 & 0.9 & 3.6 & 13.4 \\
\hline & $35-39$ & 23.6 & 76.4 & 5.3 & 0.8 & 2.9 & 11.1 \\
\hline & $40-44$ & 18.4 & 81.6 & 3.8 & 0.4 & 2.4 & 11.2 \\
\hline & $45-49$ & 21.3 & 78.7 & 1.7 & 0.7 & 2.6 & 12.1 \\
\hline & $50-54$ & 23.4 & 76.6 & 2.3 & 2.4 & 2.2 & 9.5 \\
\hline & $55-59$ & 15.3 & 84.7 & 1.9 & 1.9 & 2.2 & 9.1 \\
\hline & $60-64$ & 16.4 & 83.6 & 0.0 & 1.5 & 2.1 & 7.0 \\
\hline & $>64$ & 23.3 & 76.7 & 1.5 & 0.6 & 1.8 & 5.4 \\
\hline & Total & 20.7 & 79.3 & 5.0 & 1.2 & 3.4 & 12.1 \\
\hline \multirow{11}{*}{$\begin{array}{l}\text { Z } \\
\sum_{0} \\
\vdots \\
3\end{array}$} & $<25$ & 35.7 & 64.3 & 6.0 & 0.7 & 6.9 & 11.8 \\
\hline & $25-29$ & 31.7 & 68.3 & 3.1 & 0.7 & 4.2 & 6.7 \\
\hline & $30-34$ & 38.9 & 61.1 & 1.9 & 0.0 & 3.5 & 5.1 \\
\hline & $35-39$ & 42.2 & 57.9 & 0.5 & 0.7 & 2.9 & 5.4 \\
\hline & $40-44$ & 33.8 & 66.2 & 0.7 & 0.9 & 2.1 & 6.7 \\
\hline & $45-49$ & 31.9 & 68.1 & 0.9 & 0.2 & 2.0 & 5.4 \\
\hline & $50-54$ & 33.5 & 66.5 & 1.8 & 0.7 & 1.2 & 2.7 \\
\hline & $55-59$ & 38.2 & 61.9 & 0.0 & 0.0 & 1.1 & 3.0 \\
\hline & $60-64$ & 39.5 & 60.5 & 0.0 & 5.2 & 0.4 & 4.1 \\
\hline & $>64$ & 51.8 & 48.2 & 0.2 & 4.4 & 1.5 & 1.7 \\
\hline & Total & 39.6 & 60.4 & 1.3 & 0.7 & 3.6 & 6.4 \\
\hline
\end{tabular}

${ }^{a}$ Except for non-RBT, weighted estimates are shown in order to represent population characteristics.

${ }^{\mathrm{b}}$ Including binge drinkers. 
Figure 1. Drinkers, binge drinkers, and alcohol-impaired drivers detected in RBTs and non-RBTs (preventive and accident)

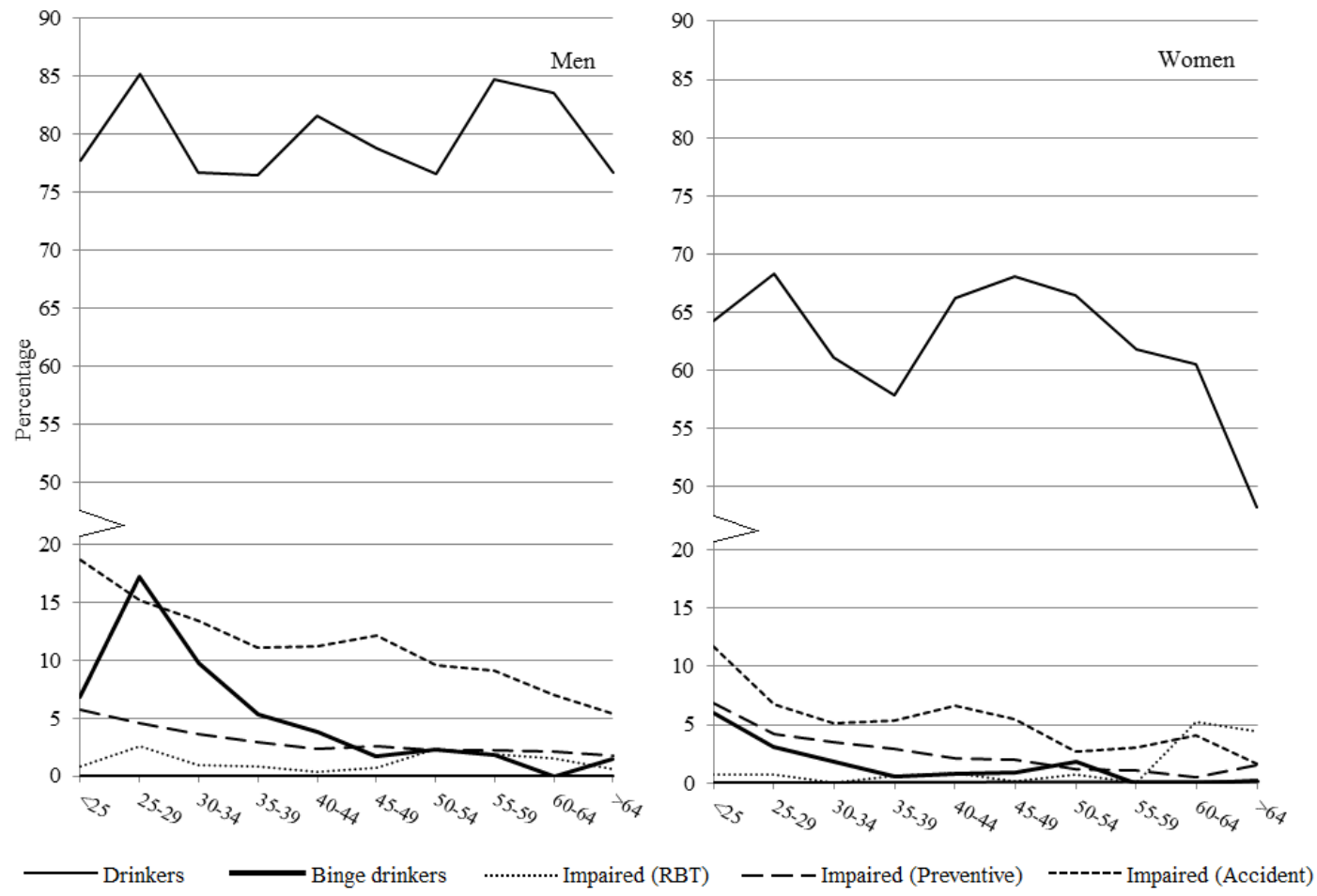

\subsection{Drinking behaviour by age and gender}

Alcohol consumption patterns by age and gender were observed. Across the lifespan, men reported consuming alcohol much more frequently than women in all age intervals. The greatest gender difference in the percentage of drinkers occurred among respondents over the age of 64 (28.5 percentage points). A similar drinking behaviour pattern was observed for both genders up to middle age. The peak in the percentage of self-reported alcohol drinkers in both genders was reached in their late 20s. In ages ranging from 30 to 39 the percentage of alcohol drinkers fell sharply, recovering partially in their early 40s. After that age some gender differences emerge. In the case of females, a downtrend in the number of self-reported alcohol drinkers with age was observed after the age of 49. And the lowest percentage of self-reported alcohol female drinkers was seen among respondents over 64. On the contrary, an increase in the percentage of male alcohol drinkers was detected in ages ranging from 55 to 64, while 
this figure fell again for individuals 64-plus, when the associated rate was similar to those observed in men in their 30s or early 50s.

The binge-drinking pattern presented a clear downtrend with age, but notable gender differences could be observed, with the number of binge drinkers in the male population being higher across all age groups. There was a large increase in male binge drinkers in the transition from their early to late 20 s, when the maximum percentage was recorded (17.2\%). Later the percentage of male binge drinkers fell sharply to their mid-40s, and thereafter ranged around $2 \%$. A change was recorded in the over $64 \mathrm{~s}$ with the percentage of binge drinkers returning to the rate that it was for males from 45 years onwards with a dip for the 60 to 64 year olds. In females, by contrast, the highest rate of binge drinkers was found among the under $25 \mathrm{~s}$ (6.0\%). Binge drinking rates also fell among women up to the age of 35 , when an upturn, ending at 54, was observed.

\subsection{Drink driving detection in random breath tests}

To examine drink driving detection rates, we first analysed the drunk-driving patterns by age and gender observed at random sobriety checkpoints. Here, BAC levels over the legal limit did not present a clear pattern in terms of the percentage of DUI offenders in relation to age. By gender, however, the percentage of alcohol-impaired males was greater in most age intervals under 60, falling at ages beyond this. Male drivers in their late 20s were associated with a higher percentage of illegal BAC levels than drivers in their early 20s. After this peak, a relatively low percentage of DUI drivers was recorded for ages ranging from 30 to 50. A sharp increase in the percentage of illegal BAC levels was observed among male drivers over the age of 50, and this figure remained relatively

high until they enter their late 60s. In the case of females, very high DUI rates were obtained at ages over 60 , though extreme caution should be exercised because of the relatively small sample of BAC tests performed in this age interval (Table 1) given the low number of elderly female drivers in the Catalan population.

The differences between the RBT outcomes and the drinking habits of the general population shed some light on the propensity to drive drunk. Figure 1 shows that among the male population the rate of alcohol-impaired drivers recorded in RBTs and the 
percentage of drinkers presented a similar pattern for young and older drivers, whereas middle-aged drivers were less frequently detected. The estimated linear correlation coefficient between the percentages of drinkers and DUI for males was 0.48 across the whole age range, but if we only considered males under 35 and over 55, the correlation coefficient rose to 0.93 . In the case of females, the correlation coefficient had a negative value of -0.61 , being heavily affected by the low percentage of women over 60 who reported drinking and the relatively high percentage of female DUI drivers detected at this age. Again, the low case numbers in the 60-plus categories and thus the correlation coefficient need to be treated with caution.

A similar analysis was conducted between the rate of self-reported alcohol drinkers and the percentage of impaired drivers detected in non-RBT controls. Here, the percentage of alcohol-impaired drivers detected at preventive non-RBT checkpoints fell with age (with no notable differences between the genders), but the percentage of self-reported drinkers remained largely steady across the age intervals, especially in the case of men. Hence, no significant relationship between these two rates was detected. The estimated correlation coefficients were not statistically different from zero at the $95 \%$ confidence level for either gender. Similarly, the percentage of drinkers - regardless of the quantity typically consumed - and the rate of DUI drivers involved in accidents presented no statistical correlation for either gender at the $95 \%$ confidence level.

\subsection{Detection of binge drinking drivers in non-random controls}

We examined the relationship between binge drinking patterns and the number of alcohol-impaired drivers by firstly considering BAC outcomes over the legal limit observed at preventive checkpoints. A common age pattern was found between the rate of DUI drivers detected at preventive sobriety checkpoints and the number of heavy episodic drinkers in the population, especially among women (Figure 1). Unsurprisingly, the group of population displaying the highest binge drinking rates (young adults of both genders under the age 35) also showed the highest detection rates for DUI offenders. However, in the case of men, the binge drinking behaviour of the youngest age groups was not fully captured by preventive breath tests, since the highest detection rate of impaired drivers was observed among those under 25, yet male binge 
drinking behaviour was accentuated between 25 and 34. Among females, a stronger relationship across the lifespan was observed as both rates decreased up to the age of 40 , with one notable difference compared to their male counterparts: at almost every age, the rates of binge drinking were lower than the DUI-offender detection rates. Only in their early 50s the increase in the rate of female binge drinking did not correlate with an increase in the percentage of DUI drivers, which might reflect difficulties in detection. Interestingly, women over 64 had a higher rate of illegal BAC levels than women aged between 60 and 64. The association between the rates of binge drinking and DUI offenders was analysed using linear correlation coefficients. A value of 0.72 was calculated for men and a value of 0.92 for women, both strongly significant.

Our analysis of non-RBTs conducted after an accident showed that both genders presented high rates of alcohol-impaired driving. Here again a decreasing age pattern was observed. This downward trend was particularly pronounced for women aged 2534. The same pattern was observed for men, but occurred at a later age. Gender differences in terms of rates of alcohol-impaired drivers showed that, in most age groups, the rates of alcohol-impaired males involved in accidents were roughly twice the female rates. We investigated whether the downtrend in the age of alcohol-impaired drivers involved in accidents correlated with the percentage of binge drinkers and a strong linear correlation was observed between the rate of binge drinkers and the percentage of illegal BAC outcomes in accidents, especially for women (0.83) but also for men (0.67).

Finally, the same analysis was conducted for the rate of self-reported binge drinking and the percentage of alcohol-impaired drivers detected at random controls. The estimated linear correlation coefficients were not statistically different from zero for either gender at the $95 \%$ confidence level.

\subsection{Age-related patterns observed in non-random breath tests}

Unlike the outcomes obtained in the random controls, the percentage of DUI offenders detected at the preventive sobriety checkpoints and in the aftermath of road accidents showed a downward trend with age. If we compare the DUI offenders detected at 
preventive sobriety checkpoints with alcohol-impaired drivers involved in accidents, the proportion of illegal BAC outcomes in accidents was much higher in all age intervals. Nevertheless, the patterns of outcomes above the legal limit by age and gender were very similar in both procedures. The linear correlation coefficient between DUI offence rates at preventive sobriety checkpoints and those collected following involvement in accidents reached 0.93 for men and 0.88 for women.

\section{DISCUSSION}

Illegal BAC levels show a downward trend with driver's age, whether DUI tests are performed at strategic locations with the aim of prevention, or after an accident involving victims. However, self-reported rates of alcohol consumption in the population remain quite stable over the lifespan, especially for men. If these non-RBT procedures are (incorrectly) assumed to provide a representative sample of drivers, and no other factors are taken into account, we might conclude that drivers are less likely to drive under the influence as they grow older. This appears to be a widely held belief; however, here we argue that further refinements are required for a more complete understanding of a population's drinking and driving patterns.

\subsection{The high-risk group of young binge drink drivers}

The diagnosis of drunk-driving patterns needs to take into consideration the drinking behaviour of young Catalans, among whom the highest percentage of binge drinkers is to be found in those under the age of 35. The young are associated with drinking patterns concentrated on and around certain days (weekends), time-slots (nights) and locations (pubs, discotheques, etc.) (Dyer et al., 1990; Kairouz et al., 2002; Kuntsche et al., 2005). The high rates of DUI presented by the young as detected in non-RBT procedures are a consequence of these drinking habits. Traffic officers typically identify such hot spots and set up preventive non-RBT sobriety checkpoints near them. As a consequence, the number of illegal BAC test results recorded by young drivers will be particularly high at non-random sobriety checkpoints. In general, preventive non-RBTs 
seem to be an effective strategy for detecting alcohol-impaired drivers with binge drinking habits, that is, the drinking behaviour associated with young adults.

The analysis of drinking and driving patterns of young male drivers shows that the highest rate of alcohol-impaired drivers is observed for drivers under 25 , whilst male binge drinking peaks at ages between 25 and 34 years. This result suggests one of three possibilities (or a combination of the three) for male binge drinkers in this age band: (i) either they are more conscious than their younger counterparts of the risks of drunk driving and so refrain from driving when drunk; (ii) or they have a greater alcohol tolerance and can consume higher quantities of alcohol before presenting BAC levels above the legal limit; (iii) or they have learned to circumvent law enforcement agents, avoiding locations and roads where they know there are likely to be checkpoints. Given that RBT outcomes over the legal limit rise significantly at ages between 25-29, the third possibility seems more likely, at least for this age range.

It should be stressed that until their mid-40s, male binge drinking rates are much higher than the percentage of preventive non-RBT outcomes over the legal limit. By contrast, rates of female binge drinkers are lower than the rates of detected DUI-offenders in nonRBTs at almost every age. Note that the definition of binge drinking for both genders in Spain is based on the same amount of alcohol consumption. Thus, the fact that the binge drinking rates of women are lower than the impaired driving rates detected in preventive non-RBT is consistent with the greater sensitivity of women to the impairing effects of alcohol (Miller, Weafer \& Fillmore, 2009). Additionally, we might conclude that the effectiveness of preventive sobriety checkpoints for detecting binge drinkers with heavy episodic drinking behaviour is the same regardless of a woman's age. In the case of breath tests conducted after a crash, women present lower rates of illegal BAC levels than those presented by men at all ages. According to Marczinski, Harrison and Fillmore (2008), the fact that their intoxication levels are self-perceived as being high may help women form correct judgments about their capacity to drive, and so deter them from taking to the road.

Alcohol-impaired young drivers are also highly involved in traffic accidents with victims. Here similar conclusions can be drawn to those presented above for preventive sobriety checkpoints, with the high percentage of illegal BAC outcomes among young 
drivers being explained in part by their driving skills (Finn \& Bragg, 1986). Young people tend to be inexpert drivers that present aggressive, risky driving behaviour (Björklund, 2008; Shinar, 1998). This careless approach to driving is likely to be exacerbated by alcohol consumption (Begg, Langley \& Stephenson, 2003; Yu, Evans \& Perfetti, 2004). As a result of their inexperience and aggressiveness, driving while under the influence may well have a greater impact on the probability of their being involved in an accident (Fillmore et al., 2008). Additionally, the particularly high linear correlation observed among women between the rate of binge drinkers and the percentage of illegal BAC outcomes in accidents would support the lower tolerance of females to the impairment effects of alcohol (Miller et al., 2009).

Finally, the expertise of traffic officers should also be stressed. The high correlation between the rate of preventive non-RBT positive outcomes and the rate of impaired drivers involved in accidents with victims seems to confirm that the criteria used by police officers for locating sobriety checkpoints and selecting drivers to perform breath tests are appropriate for detecting the profile of impaired drivers with a high risk of being involved in an accident according to their age and gender. This being the case, individuals tested at sobriety checkpoints cannot be considered representative of the population of drivers, as the location of sobriety checkpoints and the selection of the individuals is biased to test drivers with a higher probability of drinking and of being involved in an accident.

\subsection{The low-risk group of middle-aged drink drivers}

The self-reported drinking habits and RBT outcomes suggest that the middle-aged are less likely to drink and drive than young adults. In particular, the percentage of women claiming to drink alcohol falls sharply between the ages of 30 and 39. The explanation for this includes, but is not limited to, the age of maternity, with Spanish women on average bearing children in their 30s (Delgado et al., 2009). An analysis of results from random sobriety checkpoints seems to indicate that the drinking and driving behaviour of women reflect this pattern, with low percentages of DUI being observed among women in their $30 \mathrm{~s}$ with a slight rise in their early 40s. Note that a marked reduction is observed in the binge drinking of women between the ages of 25 and 39, and hence in their illegal BAC levels after accidents. In line with Ricciardelli et al. (2001), it seems 
that for women the decision to have children is strongly associated with a reduction in their alcohol consumption. A recovery, however, of moderate drinking habits among women at 39 onwards is closely reflected in the rates of alcohol-impaired driving after an accident. This might confirm that even moderate alcohol intake is quite harmful for women, who suffer alcohol-related physical and cognitive impairment at lower levels of exposure than men (Nolen-Hoeksema, 2004).

For men, the strong linear association between the DUI rate in RBTs and the percentage of drinkers does not remain steady between the ages of 30 and 50. At the age of 30, the proportion of male self-reported drinkers falls sharply, mainly because of the reduction in the percentage of binge drinkers, while RBTs find low percentages of alcoholimpaired male drivers. At the age of 40 while male drivers resume (a likely moderate) alcohol consumption, they continue to avoid driving drunk until their 50s.

\subsection{The high-risk group of older drink drivers}

Random breath tests identify older drivers as a risk group (50-64 and 60+ year olds for men and women, respectively). The propensity to drink and drive increases as male drivers grow older, which could be linked to the cessation of their role as care givers, a reduction in their family responsibilities, and finally the emancipation of children from the parental home. The same pattern is observed for women over 60 , but more caution is required due to the low number of RBT carried out to older female drivers. However, neither preventive nor post-crash controls seem to detect this population as a particular risk group, which seems to indicate that non-random controls fail to capture all the drinking patterns in a population.

Unlike the young, the elderly tend not to binge drink, presenting a more regular and moderate drinking behaviour throughout the week, while their drinking habits are typically associated with non-specific locations such as restaurants or at home (Neufeld et al., 2005). Consequently, strategic locations at which to set up sobriety checkpoints are not so readily identified by traffic agents. For both genders and all ages (except for women over 60), higher rates of DUI offenders are identified in post-crash breath tests than in preventive non-RBT and in RBT procedures. The impact of alcohol as an accident risk factor depends on the amount of alcohol consumed by the driver, but also 
on the interaction of drinking with other risk factors including, for instance, driving skills, risky behaviour or aggressiveness and irritability of drivers (Björklund, 2008; Shinar, 1998). The fact that the elderly are more experienced drivers with a safety-first attitude to driving (Scialfa et al., 2012; Shinar, 1998) could explain why this profile is not identified as a group that is at a high risk of drinking and being involved in a crash.

Unlike non-RBT procedures, random alcohol controls are designed to detect drivers that have consumed any amount of alcohol (not just binge drinkers), so they are successful in identifying older drivers as a group at risk of drink driving. The lower propensity of the middle-aged to drink and drive is relaxed in ages ranging from 50-64 (males) and above 60 (females), when relatively high percentages of DUIs are detected. In particular, the small subpopulation of women that drink seems to be less aware of the risks of drunk driving than their male coevals, as high percentages of women aged 60plus are observed driving under the influence in RBTs. Although considerable caution should be exercised due to the small number of tests conducted on female drivers in this age interval, previous studies have identified elderly women as a group at risk of drink driving (Waller \& Blow, 1995).

Increases in drink driving in elderly women should be associated with a higher proportion of alcohol drinkers at advanced ages. Geels et al. (2013) show that Dutch women consume the largest quantities of alcohol between the ages of 55 and 65 and suggest that this increase in alcohol consumption is due to the combination of a higher number of years lived in good health with a higher average income. In our study this habit among older women is not so apparent, especially after the age of 64 according to their self-reported drinking behaviour. However, the drink driving behaviour of these women (at ages 65-plus) is captured by alcohol breath tests performed at strategic sobriety checkpoints and after accidents (at ages between 60 and 64). Thus, while our results suggest that the percentage of drinkers among older women is relatively low, they are more prone to drink driving than other age groups and are detected in alcohol controls.

\section{CONCLUSIONS}


This article has centred on the trends presented by the population of Catalonia (Spain) and has sought to match information from traditional alcohol-related sources with data on alcohol-impaired driving, including random breath test samples conducted in a roadside survey. It can be concluded that preventive non-RBT sobriety checkpoints are effective in detecting drunk drivers presenting a high risk of being involved in road accidents. This group of drivers corresponds closely to self-reported binge drinkers, especially in the case of females. As such, non-random breath testing procedures seem to constitute the most effective strategy for detecting heavy episodic drinkers on the roads. However, drivers presenting a more moderate (non-binge) drinking behaviour are not consistently detected by preventive procedures following an accident. Although the probability of their being involved in a crash rises, this increase is not as great as that found for drivers with binge drinking habits. In this sense, random breath tests appear to be the best approximation of the drink-driving behaviour of the whole population of drivers. By their very nature, they provide valid information for conducting unbiased estimations of DUI rates in every age group. In addition, a comparison of BAC outcomes with the population's drinking habits would appear to be a valuable tool for identifying those ages at which individuals are most likely to drive drunk. Indeed, in the case of the male population, RBTs are the only tested procedure that correlates with drinking. Here, we have shown that such random controls are less effective at detecting binge drinkers but that they do identify other risk groups not detected when using standard non-random procedures.

The BAC information provided by preventive non-RBT sobriety checkpoints, as well as that for drivers involved in traffic accidents, is essential for understanding a population's drinking and driving behaviour. However, given the non-random (intentional) selection procedures, some groups of alcohol-impaired drivers may be overrepresented and, more worryingly, others may be underrepresented. Young drivers are typically associated with drinking behaviour that concentrates around certain days and certain locations, as well as with inexperienced and aggressive driving behaviour that is exacerbated by alcohol intake. Given that traffic officers are readily able to identify hot spots associated with the binge drinking habits of young people, they set up strategic sobriety checkpoints near them. This results in an overrepresentation of certain profiles when analysing the percentages of alcohol-impaired drivers recorded at strategic sobriety checkpoints and the number of accidents. By contrast, older drink 
drivers (50-64 year olds in the case of men and the over 60s in the case of women) may be underrepresented in traditional data sources. Discrepancies are observed among middle-aged drivers, suggesting that maternity/paternity has a great impact on drinking patterns and driving behaviour. Drivers, and particularly female drivers, reduce their alcohol consumption and seem more averse to drink driving in these age groups suggesting they adopt more careful behaviour during parenthood.

We conclude that empirical studies based on traditional non-random alcohol breath test results need to bear such limitations in mind when interpreting their findings. Studies based on multiple alcohol data sources are required to provide a more complex understanding of a population's drinking and driving behaviour in relation to their socio-demographic characteristics.

The following traffic safety policy recommendations might be made. It appears that a combination of random and non-random BAC tests would constitute the best strategy for detecting the drunk-driving population. Preventive non-RBTs are more effective in detecting drunk drivers with a high risk of being involved in an accident. Effective publicity campaigns for these controls are essential to keep these dangerous drivers off the road and to reduce alcohol-related fatalities. RBTs serve as an efficient deterrent at every age, and not solely among young drivers who know that the probability of being tested after binge drinking in leisure facilities (clubs and bars) is high. RBTs raise the probability of being stopped while driving under the influence of alcohol and this can be a major deterrent for the middle aged and the elderly.

\section{Acknowledgements}

The authors gratefully acknowledge the comments and suggestions from the editor and the anonymous referees. We wish to express our gratitude to the researchers at the UB Riskcenter, and especially to Òscar Llatje, Helena Chuliá and Montserrat Guillén, for their helpful discussions. We thank the Spanish Ministry of Education and the ERDF for grant ECO2012-35584. We also thank the Catalan Traffic Authority, the Catalan police force (Mossos d'Esquadra) and the Catalan Health Department for carrying out the fieldwork and providing the data. 


\section{Glossary}

BAC: blood alcohol content.

BrAC: breath alcohol content.

DUI: driving under the influence (of alcohol).

RBT: random breath tests.

Non-RBT: non-random breath tests.

SDU: standard drink unit.

\section{References}

Alcañiz, M., Guillén, M., Santolino, M., Sánchez-Moscona, D., Llatje, O., \& Ramon, Ll. (2014a). Prevalence of alcohol-impaired drivers based on random breath tests in a roadside survey in Catalonia (Spain). Accident Analysis and Prevention, 65, 131-141.

Alcañiz, M., Mompart, A., Guillén, M., Medina, A., Aragay, J.M., Brugulat, P., \& Tresserras, R. (2014b). New design of the Health Survey of Catalonia (Spain, 20102014): A step forward in health planning and evaluation. Gaceta Sanitaria, 28, 338-340 (in Spanish).

Begg, D., Langley, J., \& Stephenson, S. (2003). Identifying factors that predict persistent driving after drinking, unsafe driving after drinking, and driving after using cannabis among young adults. Accident Analysis and Prevention, 35, 5, 669-675.

Björklund, G. (2008). Driver irritation and aggressive behaviour. Accident Analysis and Prevention, 40, 3, 1069-1077.

Catalan Health Department (2012). Enquesta de Salut de Catalunya 2010-2014, Technical Information. Generalitat de Catalunya (available at: http://www.gencat.cat/salut/esca). 
Catalan Traffic Authority (2012). Statistical yearbook of traffic accidents in Catalonia. Generalitat de Catalunya (available at: http://www20.gencat.cat/docs/transit/Documents /informacio_viaria/Anuari_2012_ang.pdf).

Delgado, M., De Rose, A., Barrios, L., \& Zamora-López, F. (2009). The delay of maternity and its causes: an analysis of the timing of the first child in Spain. Genus, 65, $2,79-111$.

Ditsuwan, V., Veerman, J.L., Bertram, M., \& Vos, T., 2013. Cost-Effectiveness of Interventions for Reducing Road Traffic Injuries Related to Driving under the Influence of Alcohol. Value in Health, 16, 1, 23-30.

Dula, C.S., Dwyer, W.O., \& LeVerne, G., (2007). Policing the drunk driver: Measuring law enforcement involvement in reducing alcohol-impaired driving. Journal of Safety Research, 38, 3, 267-272.

Duncan, D.F. (1997). Chronic drinking, binge drinking and drunk driving. Psychological Reports, 80, 2, 681-682.

Dyer, A., Cutter, G. Liu, K., Armstrong, M., Friedman, G., Hughes, G., Dolce, J., Raczynski, J., Burke, G., \& Manolio, T. (1990). Alcohol intake and blood pressure in young adults: The CARDIA study. Journal of Clinical Epidemiology, 43, 1, 1-13.

Erke, A., Goldenbeld, C., \& Vaa, T. (2009). The effects of drink-driving checkpoints on crashes - A meta-analysis. Accident Analysis and Prevention, 41, 5, 914-923.

Fell, J.C., Lacey, J.H., \& Voas, R.B. (2004). Sobriety checkpoints: evidence of effectiveness is strong, but use is limited. Traffic Injury Prevention, 5, 3, 220-227.

Ferris, J., Mazerolle, L., King, M., Bates, L., Bennett, S., \& Devaney, M. (2013). Random breath testing in Queensland and Western Australia: Examination of how the random breath testing rate influences alcohol related traffic crash rates. Accident Analysis and Prevention, 60, 181-188. 
Fillmore, M.T., Blackburn, J.S., \& Harrison, E.L.R. (2008). Acute disinhibiting effects of alcohol as a factor in risky driving behaviour. Drug and Alcohol Dependence, 95, 1$2,97-106$.

Finn, P., Bragg, W. (1986). Perception of the risk of an accident by young and older drivers. Accident Analysis and Prevention, 18(4), 289-298.

Flowers, N.T., Naimi, T.S., Brewer, R.D., Elder, R.W., Shults, R.A., \& Jiles, R. (2008). Patterns of alcohol consumption and alcohol-impaired driving in the United States. Alcoholism-Clinical and Experimental Research, 32, 4, 639-644.

Garcell, H.G., Enríquez, T.S., García, F.G., Quesada, C.M., Sandoval, R.P., \& Villalobos, J.S. (2008). Impact of a drink-driving detection program to prevent traffic accidents (Villa Clara Province, Cuba). Gaceta Sanitaria, 22, 4, 344-347 (in Spanish).

Geels, L, Vink, J., van Beek, J., Bartels, M., Willemsen, G., \& Boomsma, D. (2013). Increases in alcohol consumption in women and elderly groups: evidence from an epidemiological study. BMC Public Health, 13, 207.

Gjerde, H., Normann, P.T., Pettersen, B.S., Assum, T., Aldrin, M., Johansen, U., Kristoffersen, L., Øiestad, E.L., Christophersen, A.S., \& Mørland, J. (2008). Prevalence of alcohol and drugs among Norwegian motor vehicle drivers: a roadside survey. Accident Analysis and Prevention, 40, 5, 1765-1772.

Homel, R. (1988). Random breath testing in Australia: a complex deterrent. Australian Drug and Alcohol Review, 7, 3, 231-241.

Isalberti, C., Van der Linden, T., Legrand, S.A., Verstraete, A., Bernhoft, I.M., Hels, T., Olesen, M.N., Houwing, S., Houtenbos, M., \& Mathijssen, R. (2011). Prevalence of alcohol and other psychoactive substances in injured and killed drivers. DRUID Driving under the Influence of Drugs, Alcohol and Medicines, 6th Framework Program, Deliverable 2.2.5. Available at: https://biblio.ugent.be/publication/1166367 (accessed 14 February 2014). 
Jones, A.W. (2010). The Relationship between Blood Alcohol Concentration (BAC). and Breath Alcohol Concentration (BrAC): A Review of the Evidence. Road Safety Web Publication, No. 15, Department for Transport, London.

Kairouz, S., Gliksman, L., Demers, A., \& Adlaf, E.M. (2002). For all these reasons, I do... drink: A multilevel analysis of contextual reasons for drinking among Canadian undergraduates. Journal of Studies on Alcohol, 63, 5, 600-608.

Kuntsche, E., Knibbe, R., Gmel, G., \& Engels, R. (2005). Why do young people drink? A review of drinking motives. Clinical Psychology Review, 25, 7, 841-861.

Lacey, J.H., Kelley-Baker, T., Voas, R.B., Romano, E., Furr-Holden, C.D., Torres. P., \& Berning, A. (2011). Alcohol- and Drug-Involved Driving in the United States: Methodology for the 2007 National Roadside Survey. Evaluation Review, 35, 4, 319353.

Löbmann, R. (2002). Drunk driving: probability of detection and its perception. Policing: An International Journal of Police Strategies and Management, 25, 4, 770788.

Marczinski, C.A., \& Fillmore, M.T. (2003). Preresponse cues reduce the impairing effects of alcohol on the execution and suppression of responses. Experimental and Clinical Psychopharmacology, 11, 110-117.

Marczinski, C.A., Harrison, E.L.R., \& Fillmore, M.T. (2008). Effects of alcohol on simulated driving and perceived driving impairment in binge drinkers. AlcoholismClinical and Experimental Research, 32, 7, 1329-1337.

McCarthy, P., \& Tay, R. (2005). Road safety, alcohol and public policy. Transportation Research Part E-Logistics and Transportation Review, 41, 5, 373-376.

Miller, M.A., Weafer, J., \& Fillmore, M.T. (2009). Gender Differences in Alcohol Impairment of Simulated Driving Performance and Driving-Related Skills. Alcohol and Alcoholism, 44, 6, 586-593. 
Naassila, M., Alaux-Cantin, S., Warnault, V., Legastelois, R., Botia, B., Pierrefiche, O., \& Vilpoux, C. (2013). Persistent effects of binge drinking on adolescent brain. Alcohol and Alcoholism, 48, Suppl. 1, 26-26.

Naimi, T.S., Nelson, D.E., \& Brewer, R.D. (2009). Driving after binge drinking. American Journal of Preventive Medicine, 37, 4, 314-320.

Neufeld, K., Peters, D., Rani, M., Bonu, S., \& Brooner, R. (2005). Regular use of alcohol and tobacco in India and its association with age, gender, and poverty. Drug and Alcohol Dependence, 77, 3, 283-291.

Nolen-Hoeksema, S. (2004). Gender differences in risk factors and consequences for alcohol use and problems. Clinical Psychology Review, 24, 8, 981-1010.

Peek-Asa, C. (1999). The effect of random alcohol screening in reducing motor vehicle crash injuries. American Journal of Preventive Medicine, 16, 1, suppl. 1, 57-67.

Rehm, J., Rehm, M.X., Shield, K.D., Gmel, G., \& Gual, A. (2013). Alcohol consumption, alcohol dependence and related harms in Spain, and the effect of treatment-based interventions on alcohol dependence. Adicciones, 25, 1, 11-18 (in Spanish).

Ricciardelli, L.A., Connor, J.P., Williams, R.J., \& Young, R.M. (2001). Gender stereotypes and drinking cognitions as indicators of moderate and high risk drinking among young women and men. Drug and Alcohol Dependence, 61, 129-136.

Robledo, T., \& Córdoba, R. (2005). Cómo actuar ante el consumo de alcohol: guía de referencia para profesionales de atención primaria. Barcelona: Sociedad Española de Medicina de Familia y Comunitaria (SEMFYC), 2-3 (in Spanish).

Room, R., Babor, T., \& Rehm, J. (2005). Alcohol and public health. The Lancet, 365, 9458, 5-11, 519-530. 
Scialfa, C., Borkenhagen, D., Lyon, J., Deschênes, M., Horswill, M., \& Wetton, M. (2012). The effects of driving experience on responses to a static hazard perception test. Accident Analysis and Prevention, 45, 547-553.

Shinar, D. (1998). Aggressive driving: the contribution of the drivers and the situation. Transportation Research Part F: Traffic Psychology and Behaviour, 1, 2, 137-160.

Spanish Traffic Authority (2012). Anuario Estadístico General. Dirección General de Tráfico, Ministerio del Interior (Document in Spanish). Available at: http://www.dgt.es /Galerias/seguridad-vial/estadisticas-e-indicadores/publicaciones/anuario-estadistico-degeneral/2014/AnGeneral_2012.pdf (accessed 25 July 2014).

Valencia-Martín, J.L., Galán, I., \& Rodríguez-Artalejo, F. (2007). Binge drinking in Madrid, Spain. Alcoholism: Clinical and Experimental Research, 31, 10, 1723-1730.

Vanlaar, W. (2005). Drink driving in Belgium: results from the third and improved roadside survey. Accident Analysis and Prevention, 37, 3, 391-397.

Voas, R.B., Romano, E., Tippetts, A.S., \& Furr-Holden, C.D.M. (2006). Drinking status and fatal crashes: Which drinkers contribute most to the problem? Journal of Studies on Alcohol, 67, 5, 722-729.

Waller, P., \& Blow, F. (1995). Women, Alcohol, and Driving. In: Recent Developments in Alcoholism, Volume 12: Women and Alcoholism. M. Galanter (ed.), New York: Plenum Press.

Wells, J.K., Greene, M.A., Foss, R.D., Ferguson, S.A., \& Williams, A.F. (1997). Drinking drivers missed at sobriety checkpoints. Journal of Studies on Alcohol, 58, 5, 513-517.

WHO (2011). Global status report on alcohol and health. Country Profiles. Geneva: World Heath Organization. 
Yu, J., Evans, P., \& Perfetti, L. (2004). Road aggression among drinking drivers: Alcohol and non-alcohol effects on aggressive driving and road rage. Journal of Criminal Justice, 32, 5, 421-430. 